\title{
Consequences of Teenage Pregnancy
}

\author{
Article by Catherine Malethola Lebina \\ MSN, Texila American University, Lesotho \\ E-mail: catherine.lebina@gmail.com
}

\begin{abstract}
Teenage pregnancy remains a challenge requiring urgent resolution the world over (United Nations Population Fund, 2013). In 2014 the World Health Organization reported that 11\% of all births were due to women aged 15- 19 years (World Health Organization, 2014). Approximately 95\% of teenage pregnancies occur in developing countries with 36.4 million women becoming mothers before age 18 (United Nations Population Fund, 2013) (Mkwananzi and Odimegwu).

All teen pregnancies are dangerous because every teen lacks the skills that are needs to handle oodles of stress that pregnancy brings along. All teen pregnancies are dangerous because every teen lacks the skills that are needs to handle oodles of stress that pregnancy brings along(Social Dynamics of Adolescent Fertility in Sub-Saharan Africa).

Main objective: The key objective of this formative research study was to compare the response got from the target audience (youth aged 15-19 years) at St Charles catchment area and St Peter H/C catchment area on the challenges they are facing with after conceiving at an early stage of life. The study also seek to find out number of teenagers delivered at the facility with or without complications.

Method: The study was quantitative descriptive cross sectional where the emphasis is on comparing groups. The study aimed to identify the relation of responses from the respondents. Data on teenage pregnancy were compiled for 2 facilities namely; St Charles Hospital and St Peter Health Centre

Results: A sample of 35 questionnaires distributed at St Charles Hospital, returned 33. St. Peter H/C (25) questionnaires were distributed to the youth who came for health services. 24 were returned of which all of them were returned. For St Charles hospital, 13.64\% were those 15 and 19 years, $22.73 \%$ were between 16-17 years, 27\% were 18 years at the time of delivery of first kids. At St Peter $\mathrm{H} / \mathrm{C}$, $23.81 \%$ were 15 years, $14.29 \%$ were at 16 and 17 years, $19 \%$ were $18 y e a r s$, and $28.57 \%$ were 19 years old when they gave birth to their first kids.

Conclusion: The results clearly indicate that teenage pregnancy occurs equally to married and unmarried females. The difference is one to make both parameters equal. $27 \%$ of the respondents gave birth at the age of 18 years. At the remote areas, teenage pregnancy is more prominent as the study shows that $23.81 \%$ had their first kids at the age of 15 from the catchment area of St Peter Health Centre.

Teenage or adolescent pregnancy is noted as a major public health and demographic problem with medical, psychological, social and demographic implications. (Shaw and McKay; 1942).
\end{abstract}

Keywords: Teenager, Pregnancy, challenges, unplanned marriage.

\section{Background}

St Charles Hospital known is a Catholic Mission situated in the North Eastern Country side of BothaBothe district in Lesotho $27 \mathrm{~km}$ away from the town. It is at the foothill of the mountain. It serves the population of approximately 14,200 residents in 30 villages. It serves 4 outreaches on monthly basis and supervises 5 health centers. The study focuses on the past year 2016.

\section{Introduction}

Teenage pregnancy remains a challenge requiring urgent resolution the world over (United Nations Population Fund, 2013). In 2014 the World Health Organization reported that $11 \%$ of all births were due to women aged 15- 19 years (World Health Organization, 2014). Sub-Saharan Africa had the highest prevalence of teenage pregnancy in the world in 2013 (United Nations Population Fund, 2013). 
The majority of countries with teenage pregnancy levels above $30 \%$ occur in sub-Saharan Africa (Loaiza \& Liang, 2013).Despite huge investments and refinement of these policies: Teenage pregnancy continues to reach crisis proportions in most African countries (UNFPA, 2010).

In Lesotho, $19 \%$ of women age 15-19 have begun childbearing: 15\% have given birth, and an additional $4 \%$ are pregnant with their first child. Trends shows that teenage childbearing has held steady over the last decade. The proportion of teenagers who have a child or who are pregnant was $20 \%$ in 2004 and 2009 compared with 19\% in 2014("Lesotho 2014 Demographic and Health Survey BOPHELO MINISTRY OF HEALTH")

In addition, teenage pregnancy has huge global policy inferences. Much has been written about sexual education. Little if any research has been conducted on learner pregnancy as a hurdle toward the achievement of MDGs and EFA goals(Ramulumo and Pitsoe).

\section{Statement of the problem}

Despite scaling up of school health services, there are still teenage pregnancy occurring at schools leading to drop out of school. This gives an impression that health education provided is not approached in a manner that behavioural is observed to the scholars.

\section{Justification of the study}

The study aims at helping Ministry of Health to be aware of the consequences of teenage pregnancy which bring complications to the growing teenager. Dropping out of school and raining the child also have a negative impact on the welfare of the teenager.

\section{Aim of the study}

To identify the major consequences of teenage pregnancy.

\section{Literature review}

The 2014 World Health Statistics indicate that the average global birth rate among 15 to 19 year olds is 49 per 1000 girls. Country rates range from 1 to 299 births per 1000 girls, with the highest rates in sub-Saharan Africa. Adolescent pregnancy remains a major contributor to maternal and child mortality, and to the cycle of ill-health and poverty.("WHO | Adolescent Pregnancy").

In Lesotho, 19\% of women age 15-19 have begun childbearing: 15\% have given birth, and an additional $4 \%$ are pregnant with their first child Teenagers in rural areas are more likely to begin childbearing than their urban peers: $23 \%$ of rural teenagers have had a live birth or are pregnant, compared with 12\% of urban teenagers("Lesotho 2014 Demographic and Health Survey BOPHELO MINISTRY OF HEALTH").

Because of the time and energy that raising children require, which interferes with the time and energy required to study and attend classes, women who bear a child during the school years often leave before they can complete their schooling(Childbearing, Hofferth, and Hayes).

Teen mothers are more likely to experience posttraumatic stress disorder (PTSD) than other teenage women, as well("Effects of Teenage Pregnancy: Mental Health").

Similarly, teenagers from the poorest households are more likely to have begun childbearing (26 percent) than teenagers from the wealthiest households (10 percent). The proportion of teenagers who have begun childbearing has not changed since the 2008-09 KDHS("Kenya 2014 Demographic and Health Survey").

According to a latest report released on December 30, 2015, some 18 African countries appear on a United Nations (UN) list of 20 countries with the highest teenage pregnancies in the world("Africa: Teen Pregnancies Haunt Africa - allAfrica.com").

Among the 21 countries with complete statistics, the pregnancy rate among 15- to 19-year olds was the highest in the United States (57 pregnancies per 1,000 females) and the lowest rate was in Switzerland (8)(Sedgh et al.).

There may be a feeling of bitterness or sadness when pregnant teens watch their peers engage in normal teenage activities which they are unable to participate in the responsibility of assuming the role of a parent at such a young age may take a toll on the emotional health of many teen mothers("Consequences of Teenage Pregnancy - Teenage Pregnancy Center"). 
Teenage pregnancy is one of modern society's evils and is a rather alarming situation. Most countries, developed, and underdeveloped, consider teenage pregnancy a social stigma. And, it can have devastating effects on the teen's social life. The negativity, the social alienation, and the financial distress can wreak havoc in anyone's life, let alone that of a teen, who isn't yet mature or strong enough to face the world.("11 Negative Side Effects Of Teenage Pregnancy On Society").

As Gustafsson and Worku (2007:2) observe, there is a high rate of teenage childbearing in South Africa. The United States, Turkey and Brazil have similar levels of around thousands of women giving birth during their teenage years. This suggests that teenage pregnancy is a global social problem which affects both developing and developed countries(Ramulumo and Pitsoe).

\section{Methodology}

\section{Study design}

The study was quantitative descriptive cross sectional where the emphasis was on comparing groups. The study aimed to identify the relationship of responses from the respondents. Data on teenage pregnancy were compiled from 2 facilities namely; St Charles Hospital and St Peter Health Centre. The sample was drawn from a defined population from the delivery records for the past year $2016,1^{\text {st }}$ January to $31^{\text {st }}$ December. Odds ratios were used to evaluate the age and parity. 26 records St Charles hospital retrieved and used, 28 records from St Peter's Health centre.

The questionnaire was also developed and administered to individuals who were considered to have had teenage pregnancy at their first pregnancy. The questionnaire was distributed evenly to the health center. There were 65 questionnaires distributed. St Charles Hospital area (40) and returned 31(77.5\% and 2 spoiled. The St. Peters health center they were 25 and returned 25(100\%) and 3 considered spoiled.

\section{Study site}

The study was conducted at St Charles Hospital situated at Botha-Bothe district within Likila Community Council, $27 \mathrm{~km}$ away from town, with the prevalence rate of $18.6 \%$ of teenage pregnancy as per 2015 mini study conducted. St Peter H/C, situated at Nqoe Community Council, still in BothaBothe district, $30 \mathrm{~km}$ away from town with prevalence rate of $20.2 \%$. The two places were accessible to the researcher. For both facilities, delivery records and questionnaires were distributed to the participants.

\section{Target population}

Teenagers from 15-19 years of age who access services at St Charles Hospital and St Peter H/C who got pregnant either for the first time or many a time participated in a study.

\section{Sample size}

A quantitative method used as a data analysis where odds ratios was a preferred method of choice. 54 charts/ records from both facilities and 58 questionnaires were used.

\section{Data analysis}

The records were retrieved in the hospital and sister health center (clinic) for the year 2016, therefore the table below presents findings within the hospital records vs Health centre results. At the age 16 only $10.7 \%$ delivered their first babies during the period under reviewed, none from the hospital. In both facilities at the age of 17 greater number of teens delivered $30.76 \%$ from the hospital and $32.14 \%$ at the $\mathrm{H} / \mathrm{C}$. Between the age of 18-19 25\% of them delivered at the $\mathrm{H} / \mathrm{C}$ and $30.76 \%$ at the hospital.

\section{6 hospital records}

Table 1. 2016 St. Peters health center (clinic)

\begin{tabular}{|l|l|l|}
\hline Ages & Normal vertex delivery & Caesarean section \\
\hline 15 & 0 & 0 \\
\hline 16 & 0 & 0 \\
\hline 17 & $8(30.76 \%)$ & 0 \\
\hline
\end{tabular}


DOI: $10.21522 / \mathrm{TIJNR} .2015 .03 .02$. Art011

ISSN: $2520-3126$

\begin{tabular}{|l|l|l|}
\hline 18 & $7(26.92 \%)$ & $3(11.53 \%)$ \\
\hline 19 & $8(30.76 \%)$ & 0 \\
\hline TOTALS & $\mathbf{2 3}$ & $\mathbf{3}$ \\
\hline GRAND TOTAL 26 &
\end{tabular}

Table 2.

\begin{tabular}{|l|l|l|}
\hline Ages & Normal vertex delivery & Caesarean section \\
\hline 16 & $3(10.7 \%)$ & $1(3.56 \%)$ \\
\hline 17 & $9(32.14 \%)$ & 0 \\
\hline 18 & $7(25 \%)$ & 0 \\
\hline 19 & $7(25 \%)$ & $1(3.56 \%)$ \\
\hline TOTALS & $\mathbf{2 6}$ & $\mathbf{2}$ \\
\hline GRAND TOTAL 28 & \\
\hline
\end{tabular}

Apart from the hospital and H/C records illustrated above, the questionnaire was developed and administered to individuals who were considered to have had teenage pregnancy at their first pregnancy. The questionnaire was distributed evenly to the health center. 35 were distributed at St Charles Hospital and 33 were returned. 25 were distributed to St. Peters health center and all returned.

Table 3 below shows the comparison of findings on marital status of each respondent during the time of giving birth.

Table 3. Marital status

\begin{tabular}{|l|l|l|}
\hline Status & St Charles Hospital & St Peter H/C \\
\hline Married & 17 & 20 \\
\hline Single & 16 & 5 \\
\hline
\end{tabular}

Table 3 clearly indicates that at St Charles Hospital teenage pregnancy occurs equally to married and unmarried females. The difference is one to make both parameters equal as compared to the health centre.

\section{Years of delivery}

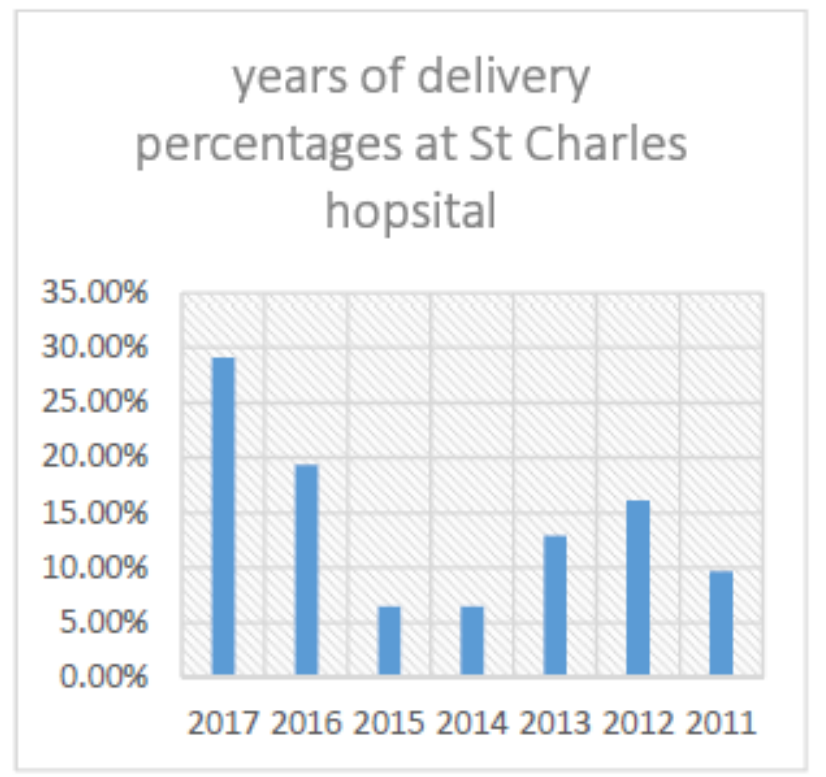

Figure 1.0 


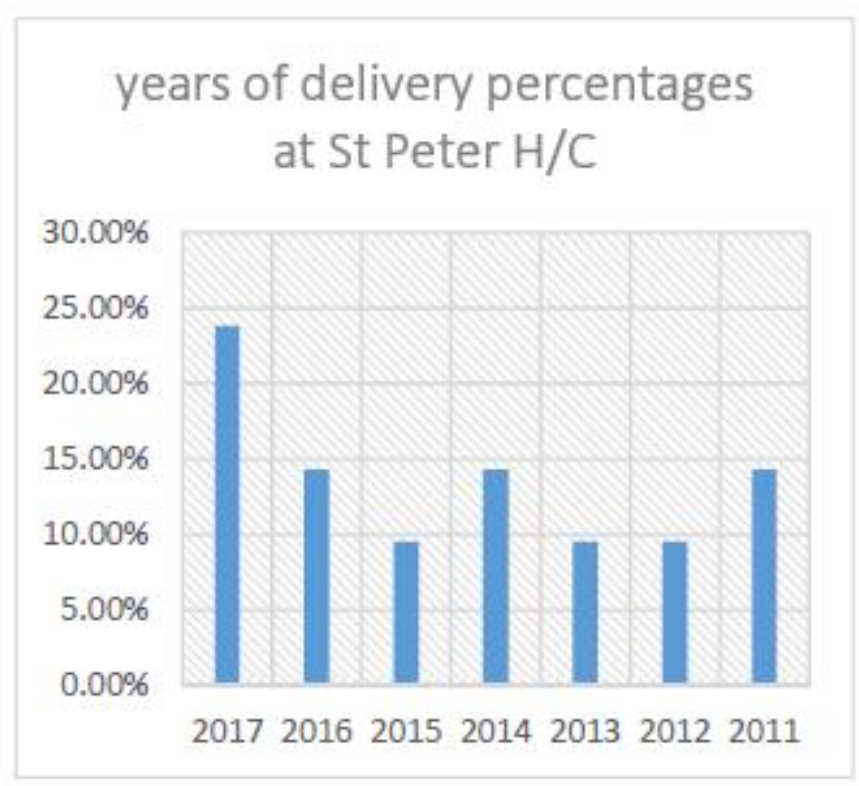

Figure 1.1

Figure 1.0 and 1.1 above display seven consecutive years in which study looked at in both health facilities as to see the trend of teenage pregnancy. This period was selected orderly without any absolute reason. However, though the study pays a focus on 2016, there is an alarming results of 2017 which seems to have increased in 6 months, indicating that by end of the year, drastic figures will be shown.

Figure 1.2 and 1.3 below show age trend at the time of delivery amongst teenage pregnancies. For St Charles hospital, $13.64 \%$ were those 15 and 19 years, $22.73 \%$ were between $16-17$ years, $27 \%$ were 18 years at the time of delivery of first kids. At St Peter H/C, $23.81 \%$ were 15 years, $14.29 \%$ were at 16 and 17 years, $19 \%$ were 18years, and $28.57 \%$ were 19 years old when they gave birth to their first kids.

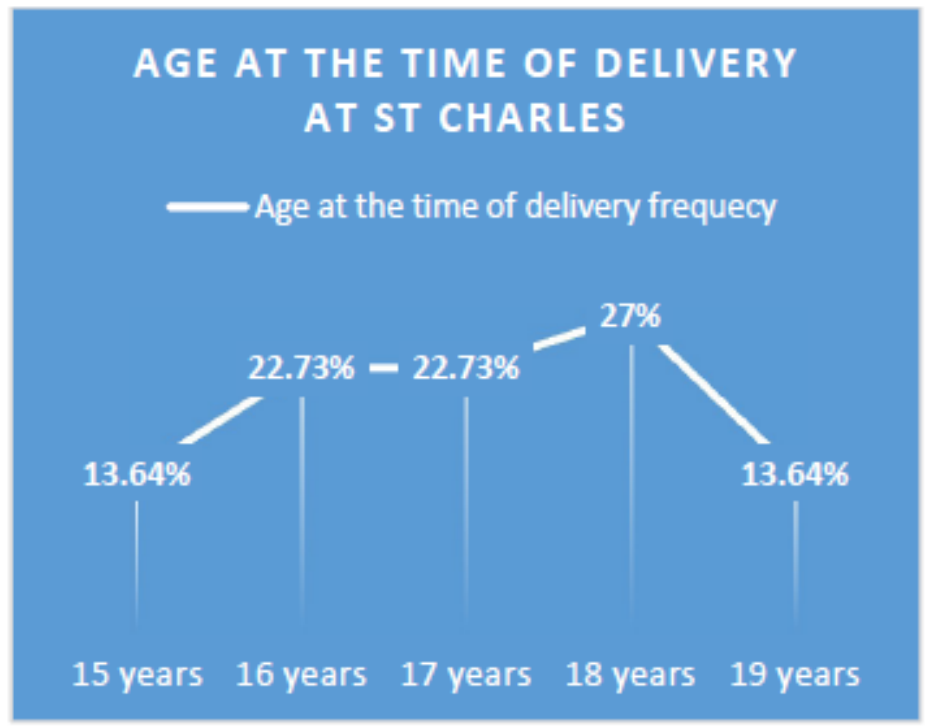

Figure 1.2 
DOI: $10.21522 / \mathrm{TIJNR} .2015 .03 .02$. Art011

ISSN: $2520-3126$

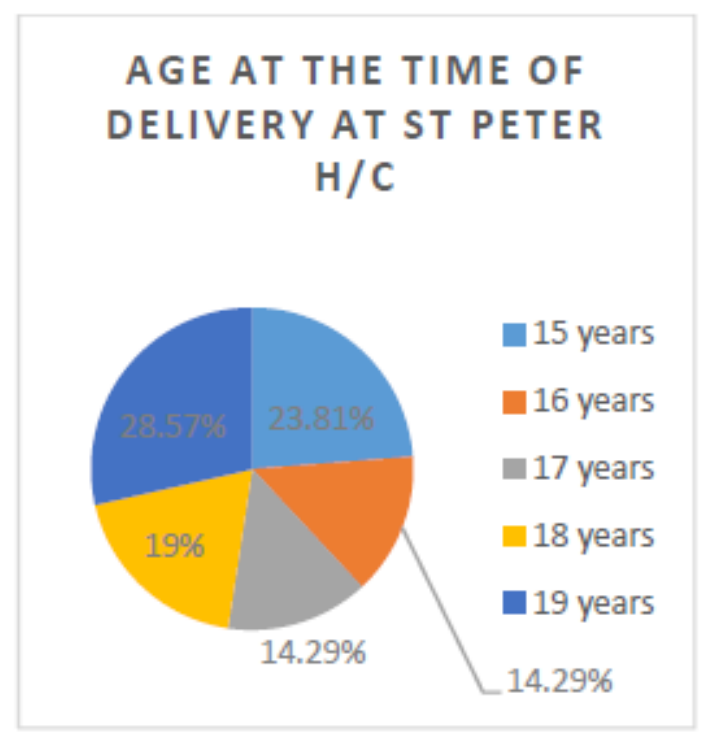

Figure 1.3

The questionnaire went on asking respondents on how many kids do they have at the moment. Table 4 below tabulates the findings and clearly indicates that $42.86 \%$ had babies for the first time at $\mathrm{St}$ Charles whereas, $48 \%$ were from St Peter H/C. Number of kids respondents have St Charles Hospital St Peter H/C.

Table 4. The place of delivery and a birth attendant were looked at by the study, therefore the findings were as follows

\begin{tabular}{|l|l|l|l|l|l|}
\hline $\begin{array}{l}\text { Respondents } \\
\text { category }\end{array}$ & $\begin{array}{l}\text { Number } \\
\text { of kids }\end{array}$ & Frequency & $\begin{array}{l}\text { Respondents } \\
\text { category }\end{array}$ & $\begin{array}{l}\text { Number of } \\
\text { kids }\end{array}$ & Frequency \\
\hline A & 1 & 15 & A & 1 & 12 \\
\hline B & 2 & 10 & B & 2 & 7 \\
\hline C & 3 & 6 & C & 3 & 5 \\
\hline D & 4 & 2 & D & 4 & 1 \\
\hline
\end{tabular}

Delivery place and birth attendants

\section{St charles hospital}

Table 5. 90.9\% of the respondents indicated clearly that they delivered at the hospital though none delivered at the health centre vs $9.09 \%$ who conducted home delivery

\begin{tabular}{|l|l|l|l|l|}
\hline $\begin{array}{l}\text { Place of } \\
\text { birth }\end{array}$ & $\begin{array}{l}\text { Number of } \\
\text { women }\end{array}$ & Birth attendants \\
\hline & & Doctors & Nurses & TBA \\
\cline { 2 - 5 } Home & 3 & 0 & 0 & $\mathbf{3}$ \\
\hline Clinic & 0 & 0 & 0 & 0 \\
\hline Hospital & 30 & $\mathbf{3}$ & $\mathbf{3 0}$ & $\mathbf{0}$ \\
\hline
\end{tabular}

\section{St peter $\mathbf{H} / \mathbf{C}$}

Table 6.

\begin{tabular}{|l|l|l|l|l|}
\hline $\begin{array}{l}\text { Place of } \\
\text { birth }\end{array}$ & $\begin{array}{l}\text { Number of } \\
\text { women }\end{array}$ & Birth attendants \\
\hline \multirow{3}{*}{ Home } & 3 & Doctors & Nurses & TBA \\
\hline Clinic & 0 & 0 & 0 & 3 \\
\hline Hospital & 22 & 0 & 0 & 0 \\
\hline
\end{tabular}


The table above shows that none of them delivered at the health center. It further shows that $88 \%$ of the teenagers delivered at the facility and $12 \%$ delivered at home assisted by traditional birth attendants.

\section{Challenges during pregnancy}

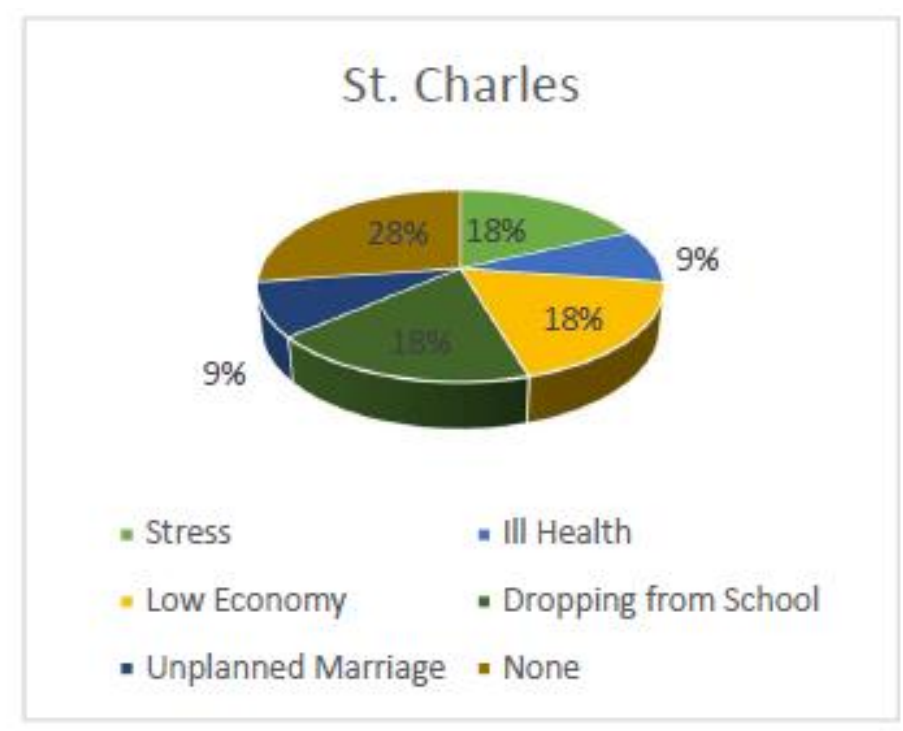

Figure 1.4

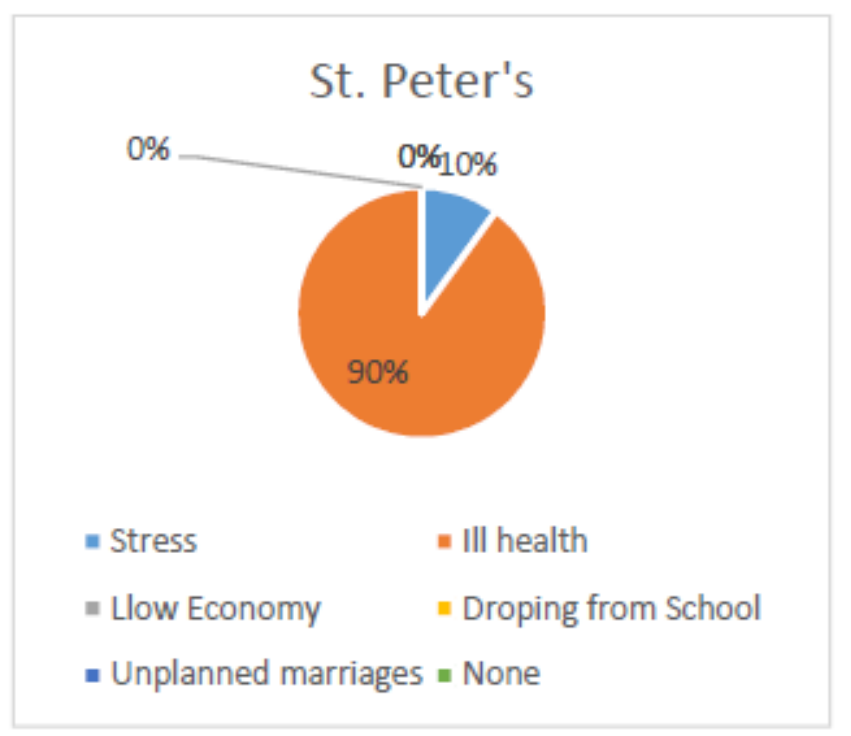

Figure 1.5

As shown in fig 1.4 and 1.5 challenges during pregnancy average of $41 \%$ did not encounter any problems during this time. However, However, St Charles Hospital shows that $18 \%$ dropped out of school, $11.43 \%$ suffered stress, $5.71 \%$ it was unplanned pregnancy. For St Peter's H/C, 90\% became ill and $4.55 \%$ dropped out of school and $10 \%$ suffered stress. It is therefore, noted that dropping out of school is applicable to both areas which hampers with normal development of the teenager. 
DOI: $10.21522 / \mathrm{TIJNR} .2015 .03 .02 . A r t 011$

ISSN: $2520-3126$

Challenges to teenagers during labour and delivery

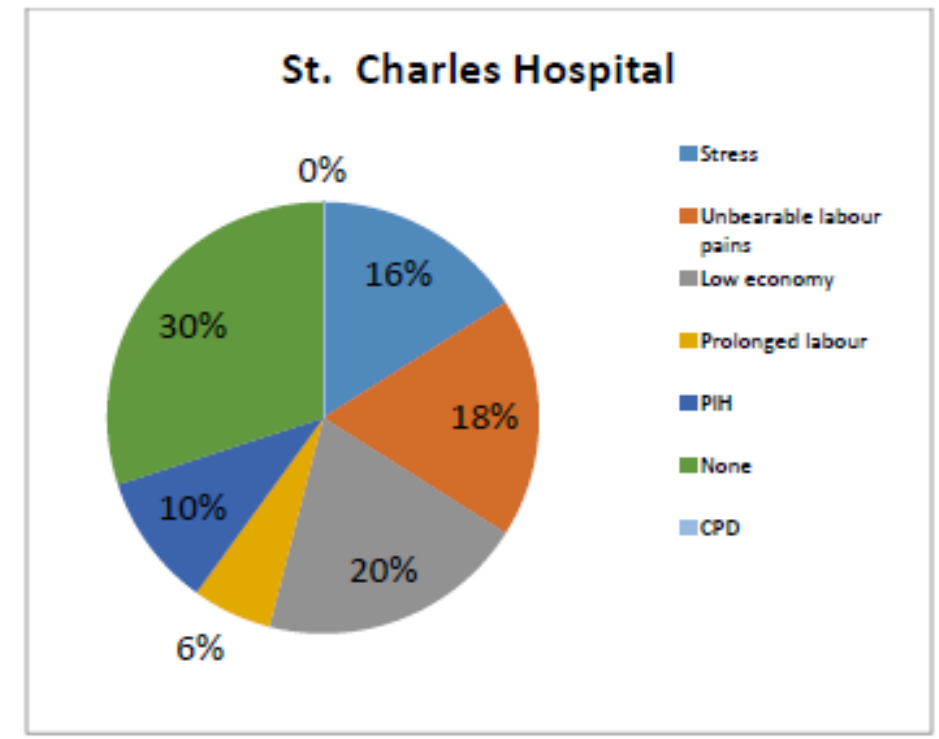

Figure 1.6

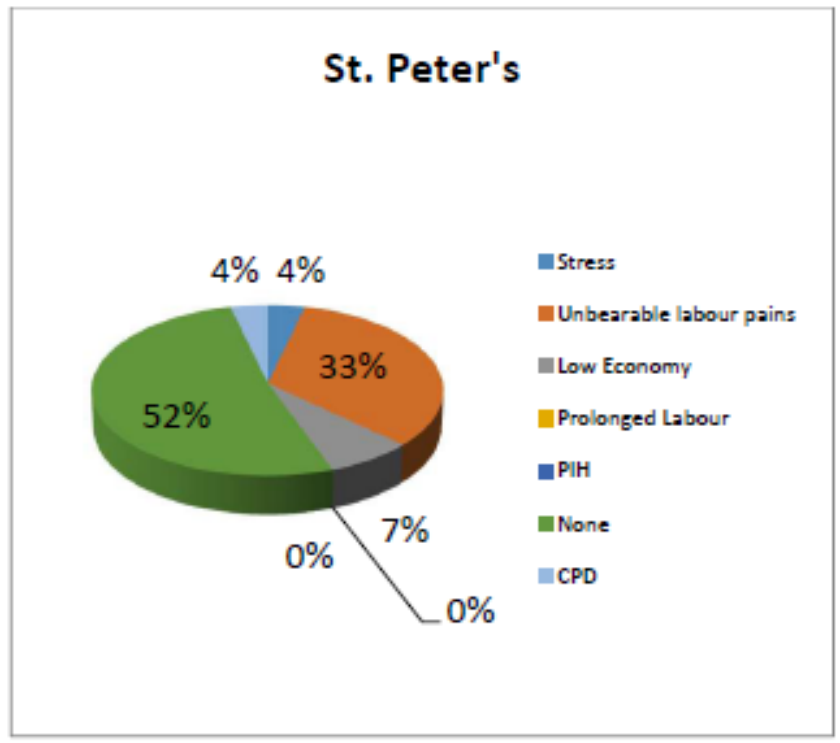

Figure 1.7

The pies above shows that an average of 30\% did not encounter any challenge during labour and delivery at St Charles and 52\% from St Peter H/C. However, some experienced unbearable labour pains at average of $25.5 \%$. Majority (16\%) of them at St Charles experienced stress and $10 \%$ suffered Pregnancy Induced Hypertension. Minority at St Peter had the above ill health. 


\section{Challenges at 6 weeks}
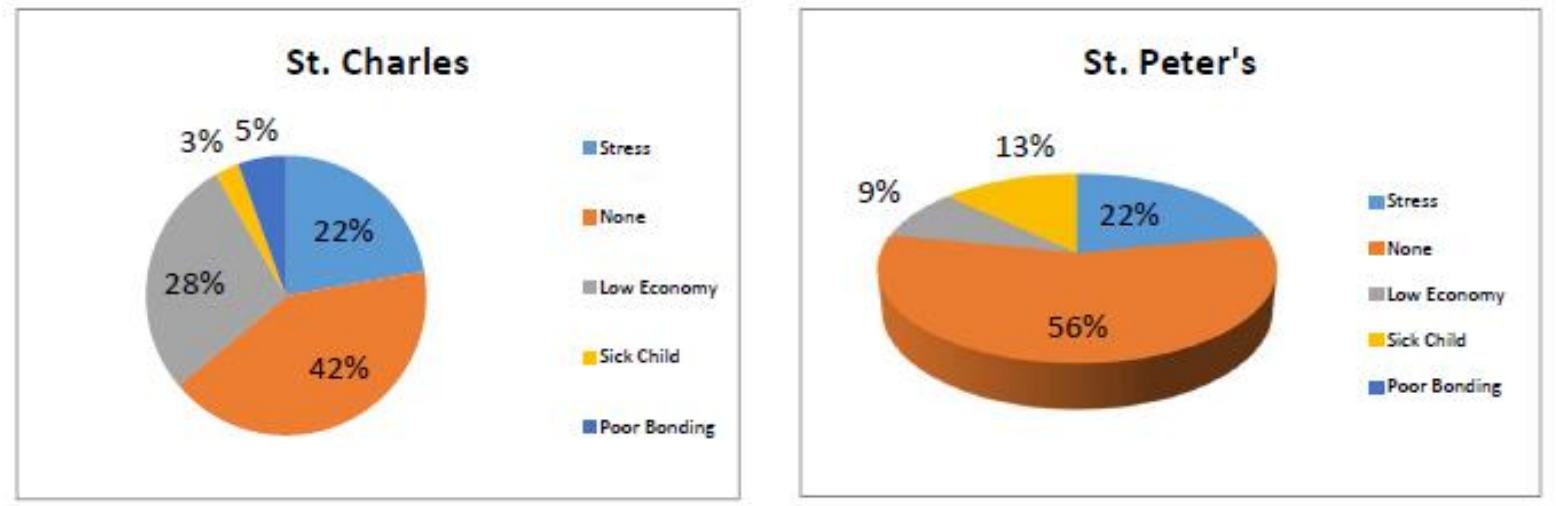

At 6 weeks, no much of the challenges were experienced. However, stress seems to be leading of $22 \%$ on both sites. Low economy also contributed at $28 \%$ from St Charles hospital and $9 \%$ at St Peter $\mathrm{H} / \mathrm{C}$.

\section{Challenges of raising the under 5 child}
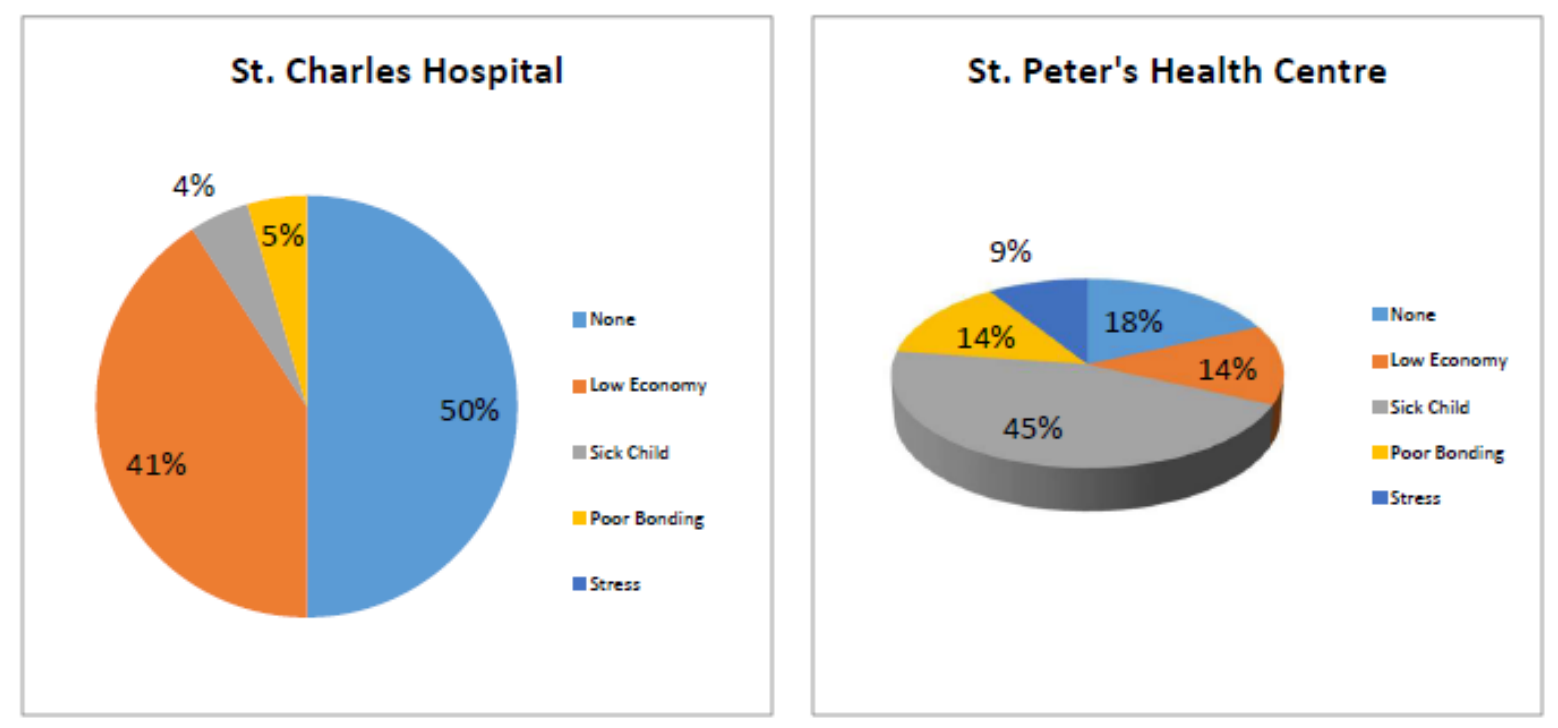

Respondents at St Peter H/C indicates that $45 \%$ of teenage mothers struggled with sick child. Poor bonding and low economy share the same results of 14\% and $41 \%$ from St Charles Hospital.

\section{Conclusion}

The results clearly indicate that teenage pregnancy occurs equally to married and unmarried females. The difference is one to make both parameters equal. $27 \%$ of the respondents gave birth at the age of 18 years. . At the remote areas, teenage pregnancy is more prominent as the study shows that $23.81 \%$ had their first kids at the age of 15 from the catchment area of St Peter Health Centre

Teenage or adolescent pregnancy is noted as a major public health and demographic problem with medical, psychological, social and demographic implications. While different theories have been tested in existing studies, the theory of social disorganisation has not been applied in investigating teenage pregnancy. The social disorganisation theory is an example of an ecological framework and posits that crime is not randomly distributed, but occurs more frequently in 'bad' neighbourhoods than in 'good' neighbourhoods (Shaw and McKay; 1942).

Many teenage mothers do not complete their high school education and this may affect their selfesteem. Due to the many concerns associated with teenage pregnancy, a large number of teens turn to alcohol and drugs. Some teen mothers may feel stigmatized by their families or ignored by their friends. There may be a feeling of bitterness or sadness when pregnant teens watch their peers engage in normal 
DOI: $10.21522 / \mathrm{TIJNR} .2015 .03 .02$. Art011

ISSN: $2520-3126$

teenage activities which they are unable to participate in("Consequences of Teenage Pregnancy Teenage Pregnancy Center").

\section{Limitations}

The study was conducted on two settings being records and use of questionnaire at the semi-rural area only. There is a need to revise the questionnaire and ensure that it is very simple and straight to the point.

\section{Recommendations}

- There is a need to conduct a study on a larger scale including both rural and urban people for proper comparisons.

- Engagement of all stakeholders to handle this global issue

- Revival of Adolescent health corners is crucial

\section{References}

[1]. "11 Negative Side Effects of Teenage Pregnancy on Society." N.p., n.d. Web. 26 Aug. 2017.

[2]. “Africa: Teen Pregnancies Haunt Africa - allAfrica.com.” N.p., n.d. Web. 1 June 2017.

[3]. Childbearing, National Research Council (US) Panel on Adolescent Pregnancy and, Sandra L. Hofferth, and Cheryl D. Hayes.

[4]. CM kwananzi, Sibusiso, and Clifford Odimegwu. "Teen Pregnancy in Sub-Saharan Africa." n. pag. Web. 1 June 2017.

[5]. "Consequences of Teenage Pregnancy - Teenage Pregnancy Center." N.p., n.d. Web. 26 Aug. 2017. ---. N.p., n.d. Web. 29 Aug. 2017.

[6]. "Effects of Teenage Pregnancy: Mental Health.” N.p., n.d. Web. 24 Aug. 2017.

[7]. "Kenya 2014 Demographic and Health Survey." n. pag. Web. 24 Aug. 2017.

[8]. "Lesotho 2014 Demographic and Health Survey BOPHELO MINISTRY OF HEALTH." n. pag. Web. 24 Aug. 2017.

[9]. Ramulumo, Mashudu R., and Victor J. Pitsoe. "Teenage Pregnancy in South African Schools: Challenges, Trends and Policy Issues." Mediterranean Journal of Social Sciences (2013): n. pag. Web. 27 Aug. 2017.

[10]. "SOCIAL AND ECONOMIC CONSEQUENCES OF TEENAGE CHILDBEARING." (1987): n. pag. Web. 24 Aug. 2017.

[11]. Sedgh, Gilda et al. "Adolescent Pregnancy, Birth, and Abortion Rates across Countries: Levels and Recent Trends." The Journal of adolescent health : official publication of the Society for Adolescent Medicine 56.2 (2015): 223-30. Web. 1 June 2017.

[12]. Social Dynamics of Adolescent Fertility in Sub-Saharan Africa. Washington, D.C.: National Academies Press, 1993. Web. 24 Aug. 2017.

[13]. "WHO | Adolescent Pregnancy.” WHO (2016): n. pag. Web. 1 June 2017. 